\title{
SPATIALLY BLIND OR PLACE BASED POLICY? A COMPARISON OF INNOVATION SUPPORT IN THE CZECH AND SLOVAK REPUBLIC
}

\author{
Miroslav Šipikal, Valéria Szitásiová, Peter Pisár, Mária Uramová
}

\section{Introduction}

A Cohesion policy as well as innovation support is one of the main criteria and objectives of the European Union. Alarge part of these two policies are supported together through Structural funds. The past decade has witnessed a gradual shift from policies aimed at reducing disparities towards those aimed at strengthening regional and national competitiveness, with a focus on exploiting regional potential to contribute to national growth (Barca, 2009). Along with the issues of developmental support and related policy responses, studies dedicated to the role of innovation in this process represent a significant part of literature from the last three decades (Asheim, 1996).

Within a cohesion policy, we found two streams of thought about the present policy along with fierce debate about whether it should be „spatially blind“ or "place based“ including factors that influence success of these policies (OECD 2009a; 2009b; World Bank, 2009; Barca, McCcann, \& Rodriguez, 2012). The first approach in general does not support the regionally targeted interventions and favours space-neutral policies with universal coverage in every territory. From this perspective, spatially-blind policies are also seen as "peoplebased" policies, representing the best approach to guarantee equal access to opportunities, regardless of where they live (Barca, McCcann, \& Rodriguez, 2012). One of the key arguments is also the importance of developing the support instruments that do not exclude or discriminate against any group of potential beneficiaries. Using such a policy, it is possible to largely create conditions for development as well as to accept and adapt to the natural circumstances in the business environment (Foray, 2014). It is assumed, by encouraging mobility, that spatially-blind strategies ultimately lead to a more even geographical distribution of wealth and a convergence of lagging areas. Consequently, development intervention should be space-neutral and production factors should simply encourage a move to where they are most productive (Barca, McCcann, \& Rodriguez, 2012).

The second strategy would stress regionalspecific interventions and argues that properly designed place-based, not "one size fit all" policies are necessary for exploiting the full potential of economic development (Tödtling \& Trippl, 2005). The starting point of a placebased policy is the idea that most of the knowledge needed to fully exploit the growth potential of a place and to design tailor-made institutions and investments is not readily available and must be produced through a new process involving all local and external actors. The place-based approach is therefore designed specifically to identify and build on the embedded local knowledge (Barca, McCann, \& Rodriquez Pose, 2012).

Empirically, the traditional approach to regional policy is still popular in some member states where a place-based approach is still in the beginning, focusing on financial transfers to firms to compensate for their higher unit capital costs and on public works. In these situations, although cohesion policy funds are not earmarked to sectors, a large part of the resources ends up being allocated to sectoral programmes that lack place-baseness. This is particularly the case for resources - about two thirds of the whole budget is managed by the central administrations (Barca, 2009).

However, only few papers are looking at empirical evidence of spatially neutral or place based policies and mainly in the form of case studies (Ortega \& Argilés, 2012; Foray, 2014). This paper is devoted to evidence of spatially neutral policies fostering innovation in two Central European countries, the Czech 
Republic and Slovakia, supported from cohesion policy instruments. In the first part we discuss theoretical concepts we relied on for the evaluation. In the methodology, the objectives of the research are explained and the research questions defined. As such, we are trying to answer these questions through the analysis of specific measures for boosting innovation in both analysed countries. The analytical part presents results of empirical evaluation of innovation support, with particular emphasis on regional and sectoral distribution.

\section{Theoretical Background}

The support of innovation is one of the most debated issues in regional policy, which is a part of the key factors of development and a source of comparative advantage (Asheim, 1996). This is evidenced by the fact that the European Union and national states allocate huge amounts of resources to promote respectively innovation, research and development. The importance of innovation is declared in scientific literature dealing with its role in regional growth. "If we are to understand why some regions grow and others stagnate, we need to understand the interactions among economic growth, economic geography and economics of innovation." (Acs \& Varga, 2002). However, there are different views on how to set up their support in order to achieve the desired impact and results of support measures. The above mentioned debate about placebased versus space neutral policies is highly discussed in innovation support policies. The role of regions in innovation activities could be found in concepts such as innovation districts (Markusen, 1996), regional innovation systems (Cooke, 1997) or learning regions (Asheim, 1996). Contemporary theoretical and practical approaches focused mainly on concept of smart specialization; (Barca, McCann, \& Rodriquez Pose, 2012; Foray, 2014) point to the fact that form and type of support should be tailored to individual regional conditions (Capello \& Lenzi, 2013; Šipikal 2013).

Another line of discussion deals with adequate distribution of cohesion funds. In both mentioned approaches (spatially blind and place based) the focus has moved towards policies that strengthen aggregate economic growth. Equity issues are addressed as part of the growth package in space-neutral policies (World Bank, 2009). However, according to the principles of the EU cohesion policy, assistance should be directed to the poorest regions, whether these regions are defined by GDP per capita relative to the European average, distribution of structural funds as a ratio of GDP or through other more appropriate socio-economic factors (Crescenzi, 2009; Dall'erba \& Le Gallo, 2008). However, experience and analyses of the distribution of aid do not always confirm compliance with the principle of concentration at lower levels. The issue of concentration of assistance in relation to the level of regional development was analysed in the context of other 10 European countries. It turned out that the spatial distribution of European Union funds is not always proportional to the level of socio economic development of regions. On the one hand, it may mean that GDP per capita is not always the most appropriate indicator for the distribution of aid. On the other hand, if the policy does not respect the principle of concentration, it could be considered as not being a successful implementation (Crescenzi, 2009). According to the analysis of the distribution of aid between regions in the Slovak Republic from the 21 most-funded districts, only four belong to the group of least developed (marginal) regions. Similar results appear when determining the concentration of support. Along the 79 districts of Slovakia the aid is concentrated primarily in 18 districts. Of these 18 districts, only three are marginal (Michalek, 2014). In this context both in literature as well as in political circles we came back to the question, whether the policy has to be so called spatially blind-placeneutral or place-based. Part of this discussion is also the question of whether support policy should be sectoral or regionally oriented, and whose form bring better results and impact on development of regions.

Several evaluation studies analysed the support of innovation in Central and Eastern Europe. The policy of innovation support (or support for research and development) passed through a number of countries and regions in different phases and various forms (Šipikal, Pisár, \& Uramová, 2010). Cohesion policy is represented in most countries by key funds for innovation support and also important institutional capacity building (Suurna \& Kattel, 2010; Felixova, 2012). Regarding the share of innovation support on the total amount of support in the country, disparities can be seen in the V4 countries. In the previous programming 
period of 2004 to 2011 of the total support in Poland $18.8 \%$ were allocated to research, development, innovation and entrepreneurship and in the Czech Republic 18.3\%. However, this share was $16.3 \%$ in Hungary and the latest indicator in Slovakia was only $12.2 \%$ (Spišáková, 2011).

Based on the above mentioned paradigms, there are three dilemmas of distribution for European Union funds. The first question is whether the policy should be place-based or space-neutral. The second question is whether the policy should be more directed to the lagging regions. The third question is whether support distribution is followed by its declared objectives. Therefore we will analyse the used regional policy instruments promoting innovation in the Czech Republic and Slovakia. We looked at type of policy used and empirical results of this policy. Part of our research puts into confrontation the planned (desired) promotion and real distribution of funds to these areas. In this context we will examine European Union development assistance in the following sections of the present article.

\section{Methodology}

The main aim of this research is to evaluate innovation support in Slovakia and the Czech Republic that is funded by the European Union resources from the regional and sectoral point of view. In this regard, the following research questions were stated: "Where are the funds using the spatially blind policies actually heading - was the support directed to the least developed areas of Slovakia and the Czech Republic? Was the support directed to sectors with higher added value in these countries? What are the main differences and similarities between the two analysed countries?"

The reason for selecting the two countries is the long common history, the same accession time into the European Union, and similarities in statistics of innovation - both are moderate innovators and pursuant to the Summary Innovation Index are below the EU average; both show similar development in this index. The principal reason of this option is that we found in both countries very similar instruments for promoting innovation, similar territorial and administrative division of the country and a detailed support system of development. In order to obtain a relevant comparison of policies in two neighbouring countries, we have chosen to analyse two similar measurements of innovation support.

In Slovakia, under the framework of the Operational Programme Competitiveness and Economic Growth, we will analyse the measure 1.1. Innovation and Technology Transfers, namely the Sub-measure 1.1.1 Support for Introducing Innovation and Technology Transfer (a state aid scheme to support the introduction of innovative and advanced technologies in industry and services). Within this sub-measure we analyse six calls for grant applications for businesses in Slovakia. These calls (KaHR111SP-0801, KaHR-111SP-0902, KaHR111SP-1001, KaHR-111SP/LSKxP-1101, KaHR111SP-1101, KaHR-111SP) were announced in the years 2008, 2009 and 2010, 2011 and 2012. They were the only projects of state assistance analyzed (not schemes de minimis). Through available information (from the Ministry of Economy of the Slovak Republic and Slovak Innovation and Energy Agency) a database of approved projects was established that was amended by particular characteristics (year of establishment, legal form, NACE Classification, number of employees, etc.) from the Register of Financial Statements of the Ministry of Finance of the Slovak Republic and the Statistical Office of the Slovak Republic.

In the Czech Republic, under the framework of the Operational Programme Business and Innovation, we will analyse measure 4.1 Increasing the innovative performance of firms, namely the sub-measure "Innovation Innovation Project". The institution responsible for its implementation is the Ministry of Industry and Trade. The intermediate body for support realization is the Investment and Business Development Agency (Czechlnvest). Within this measure we evaluate 4 calls for grant applications for businesses in the Czech Republic. These calls (Innovation - Innovation Project Call I, II, III and IV) were announced in the years 2007, 2008, 2009 and 2010. The last call has been subsequently extended to years 2011 and 2013.

To compare sectoral and regional distribution of aid we used basic descriptive statistics. We used NUTS III level, which consist of self-government administrative unit in both countries. According to the available statistics we analysed the amount of aid in both countries with respect to the number of assisted firms, number of approved projects, and amount of 
aid in terms of selected firm characteristics as well as territorial and sectoral aspects. For the conversion of Czech currency to Euro, the exchange rate of the Slovak National Bank at the time of analysis (27.08 CZK/EUR) was used.

When analysing the support of the hightech sectors, we used the definition given by Eurostat. The high tech sector includes industries with NACE code 21, 26.30 and medium-high sector with NACE code 20, $25.4,27,28,29,30,32.5$. When analysing the support of innovation poles, we used the definition given by national strategic reference framework (MVaRR SR, 2007). This analysis was made on the level of cities, compare to all other analysis done on NUTS II level.

\section{Results of Innovation Support Evaluation}

The importance of comparing two investigated neighbouring countries is highlighted in several policy analyses of European Union resources (Bruno, 2005; Spišáková, 2011), starting over from historical reasons to other socio-economic factors. In the following part of the article we proceed with the comparison of basic statistical indicators of both countries in connection with their innovative activity. In further subsections we approach to the analysis of specific measures for boosting innovation in the Czech Republic (hereinafter $\mathrm{CR}$ ) and Slovakia (hereinafter SR) in terms of regional and sectoral perspective of aid distribution and other aspects.

What will follow is an analysis of the two countries of Central and Eastern Europe with a long common history, which joined the European Union at the same time (01.05.2004). After the breakup of the Czech and Slovak Federal Republic in 1993 two sovereign states, the Czech Republic (approx. 10.5 mil. inhabitants) and the Slovak Republic (about 5.4 mil. inhabitants) were created. Due to the common history, there are many similarities in major economic indicators such as GDP (GDP per capita in PPS Index $(E U 28=100) 2015$ CR 84, SR 76) or the average monthly salary (2015 Euro - CR 934.49 Euro; SR 839 Euro). According to the Innovation Scoreboard 2014 both countries belong to the group of moderate innovators with a Summary Innovation Index for the Czech Republic 0.447 and Slovakia 0.36 and growth rates of summary innovation index for the Czech Republic $2.61 \%$ and Slovakia
$1.91 \%$. The index values of both countries are below the European Union average. At the beginning and end of the period the trends in the index of both countries are the same, but in the period between the years 2009 to 2012, these countries have different statistics. While the value of Summary Innovation Index rose slightly in the Czech Republic, there was first a decline in Slovakia, but from 2011 to 2012 moderate growth was observed.

\subsection{Selected Measures of Innovation Support in the Czech Republic and Slovakia}

Promotion of innovation through the European Union regional policy is getting increased attention in every country, due to the significant funding that is available. In both analysed countries, specific measures were identified with promotion of innovation - in the Czech Republic the measure "Innovation - Innovation Project" (hereinafter IIP CR) and Slovakia the measure "Innovation and Technology Transfers" (hereinafter ITT SR).

The two analysed measures have many similar characteristics, starting with the aims of interventions, thus enhancing the competitiveness and innovation potential of supported enterprises along with the development of sustainable and ecological production. There is also a similarity with regard to the eligible beneficiaries. Both measures are designed for small and medium-sized enterprises as well as large companies with up to 1,000 employees. This research was based on data from the Slovak Republic Ministry of Economics and Czech Invest.

The guide for applicants in Slovakia contains a list of economic sectors which are not eligible for assistance, including fishing, shipbuilding, coal and steel industry, synthetic fibres production and selected activities in agriculture and manufacturing providing dairy products. It is identical to measures from the Czech Republic, but in IIP CR, there are manually added NACE codes of activities that can be supported (eligible selected classes were from sections $C, E, J, M$ and $S$ ). This is a significant difference from the Slovakian support definition that could influence the distribution of aid.

The application (in both countries) should also contain, in addition to basic identification data, other characteristics (desired types of 
data that are not identical in two countries), the number of employees, turnover and total value of annual assets during the last financial year preceding the application. The structure of revenues, share of the largest purchaser of total production and others should also be noted. However, the beneficiaries may not include enterprises in financial difficulty or undergoing restructuring.

Eligible Regions are convergence areas in Slovakia, which means that aid can be implemented in NUTS 2 regions of Western, Central and Eastern Slovakia. The maximum duration of projects in Slovakia is set at 24 months, the intensity of aid, however, is different for different regions, ranging between $0-50 \%$ of the support from total project budget. Regarding the Czech Republic, the defined eligible NUTS 2 regions are - Central Moravia, the Northwest, Central Bohemia, MoraviaSilesia, Northeast, Southeast and Southwest, while the intensity is, as in the case of Slovakia, different for each region ranging from 30 to $60 \%$. For both countries, the assistance cannot be implemented in capital cities (it does not mean that firms registered in Prague and Bratislava are not eligible entities - more important is the place of implementation).

Regarding the ITT SR measure, measurable indicators to be pursued during and after the project execution are the socalled results indicators (growth in sales) and impact indicators (number of new jobs created and an increase in added value). In the case of IIP CR, there are more indicators required. The first group consists of the so-called binding indicators - the number of new or innovative products on the market; the number of new or innovative products put into production or service; introduction of new organizational methods in firms and co-operation with other firms and public institutions; and the number of established new sales channels. The second group consists of the so-called monitoring indicators, namely the number of newly created jobs (including women and / or research and development employees). Total sales, sales of innovative products, value added, average number of employees and labour productivity per employee are also tracked. The range of indicators in the Czech Republic is much broader and gives a more detailed picture of the situation than the generally defined indicators in Slovakia.
The evaluation process of all applications in the case of ITT SR consists of two phases, namely the formal and technical evaluation. In the first process, it is evaluated whether or not the application meets the formal requirements. The second phase is carried out by an expert committee. This committee analyses the application for aid according to the so-called evaluation criteria (basic criteria, suitability and effectiveness, method of implementation, budget and efficiency, administration, professional and technical capacity and sustainability of the project). Compared to the Czechs, there are differences. The evaluation process of IIP CR takes place using two sets of criteria. The first group consists of the so-called binary criteria (e.g. financial health of the applicant and other indicators with YES or NO responses) and the second group consists of the criteria to be used in assessing the innovative parameters of the projects.

Regarding the innovation support system itself, they primarily use very similar procedures in both analysed countries with differentiation of only some minor details of support settings. As we can see, the most important finding for our analysis is that the two policies are set as national policies, without any special assessments of regional characteristics. The criteria are set to select the best projects for the promotion of innovation, regardless of region. The application is, in principle, a spatially blind policy. The next section will examine whether the distribution of support is similar to the support system in the Czech and Slovak Republic.

\subsection{Selected Characteristics of Analysed Measures}

For analysis of the two similar measurements of innovation support, the total of $€ 821,588,884.79$ from the Czech Republic and $€ 365,483,003.69$ from Slovakia were allocated during the approved programme period of 2007-2013. Overall, there were 1,269 projects approved in the Czech Republic representing 930 companies and 400 projects in 371 companies in Slovakia. The project with the lowest support in the Czech Republic was $€ 36,927.62$ while in Slovakia, it was larger with $€ 50,590.32$. The project with the highest level of support in the Czech Republic was approx. $€ 5,539,143.28$ and in Slovakia it was similar with $€ 5,998,810.98$. The average funding amount for projects in the 
Czech Republic was $€ 659,443.10$, and again Slovakia was higher with $€ 913,707.51$. During the mentioned programming period several different calls were issued. Within the calls, a slight increase in the number of approved applications for aid was generally observed and also in the level of support in both analysed countries. In the Czech Republic, the first call had approval of 78 projects in 2007, 158 in 2008, 132 in 2009 and lastly, there was a call for an extension in years 2010, 2011 and 2013 with 901 approved applications. Slovakia was also showing a growing trend with only 25 approved projects in 2008, 66 in 2009, and in the third call 35 . However, within two calls in 2011, there were 98 applications and in the last call 176 projects were approved.

\section{Analysis of the Distribution of Support}

The total support was rather unevenly distributed at the regional level. In figure 1 we can see the calculated amount of aid per capita. The difference between the most and the leastfavored regions is more than three times.

\section{Fig. 1: Regional distribution of support per inhabitant in Czech Republic and Slovak Republic in euros}

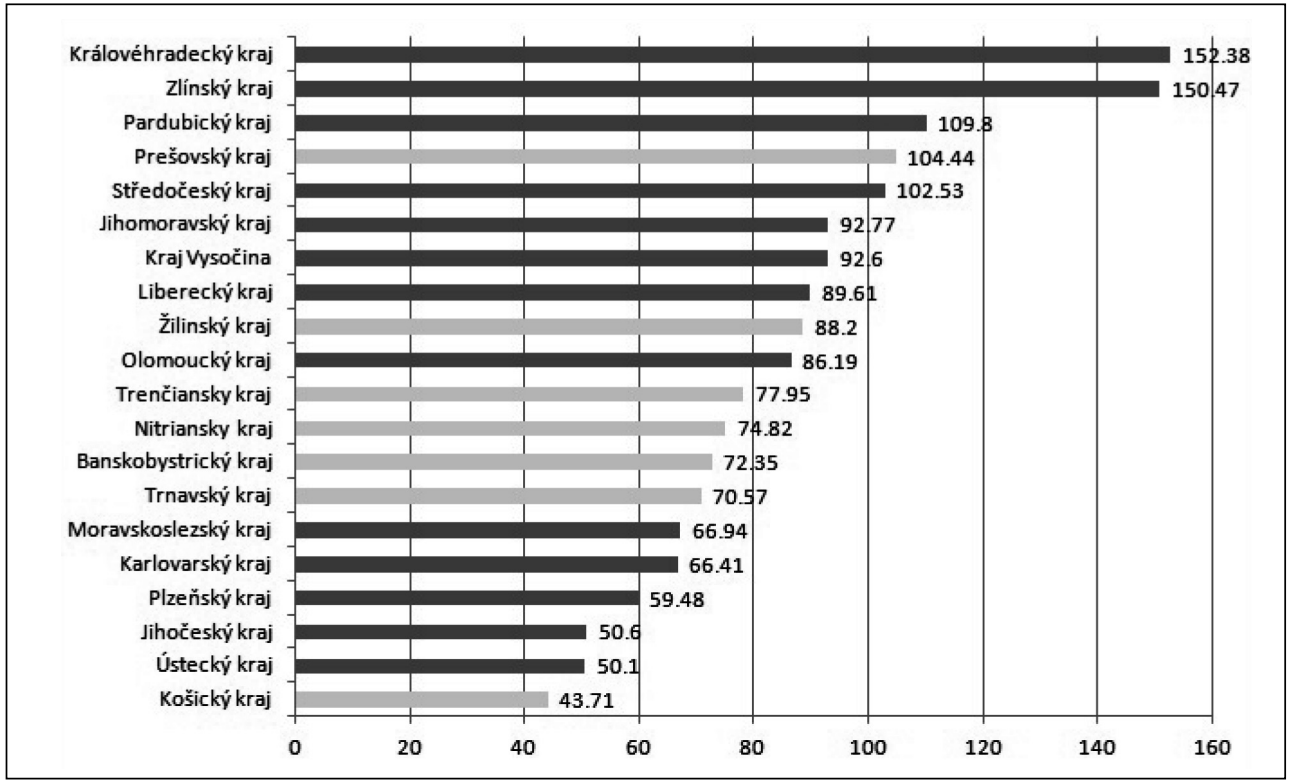

(The term "kraj" means region, darker grey are Czech regions, lighter grey are Slovak regions)

The results thus show a very different regions' ability to obtain funding from the EU to promote innovation. The principle of spatially neutral policies would support the argument that the more developed regions have the ability to create better quality and more supportable innovation projects. If we look at the proportion of the support received in terms of more vs. less developed regions, there is an interesting difference between the two countries. While the Czech Republic support approximately follows their level of development (measured in total
GDP in region), the Slovak Republic support were more targeted to disadvantaged regions. The correlation between share of support and relative share of GDP of the supported regions were 0.78 in Czech Republic, but -0.59 in the Slovak Republic. So despite the similar spatially neutral criteria, the support was distributed in very different direction.

The similar results could be found if we replace GDP by share of employment in industry. These results are shown in figure 2 and 3 . 


\section{Ekonomie}

Share on number of employees in industry (2013) vs. share of innovation support by regions in the Czech Republic

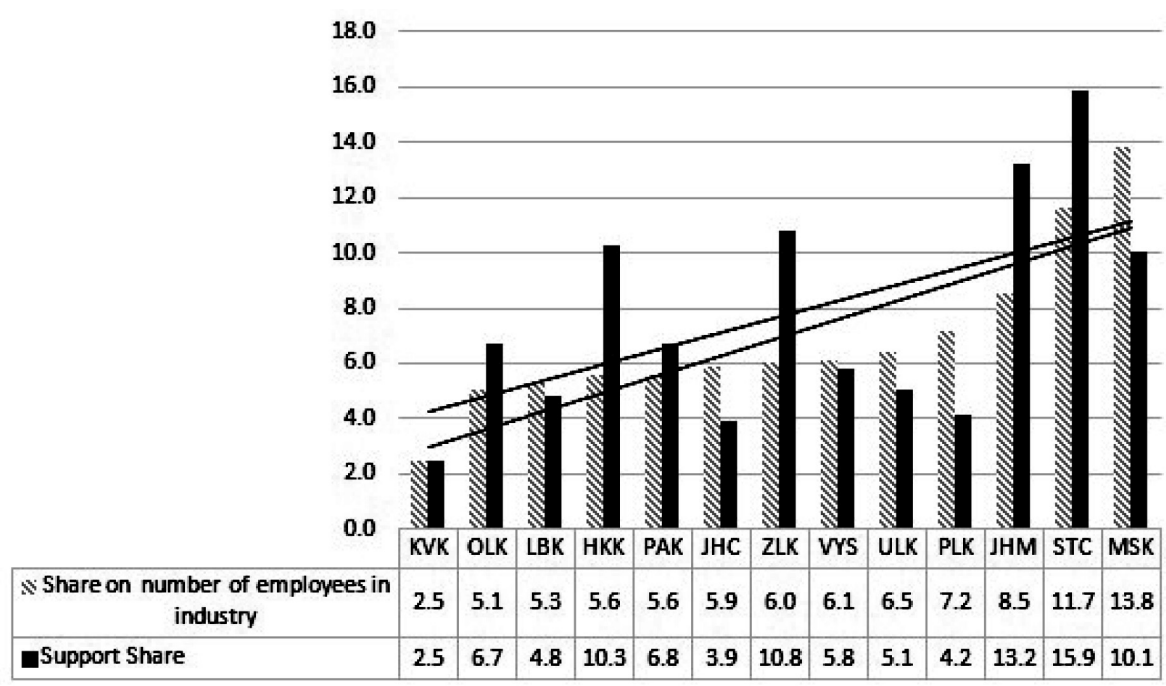

Share on number of employees in industry (2013) vs. share of innovation support by regions in Slovakia

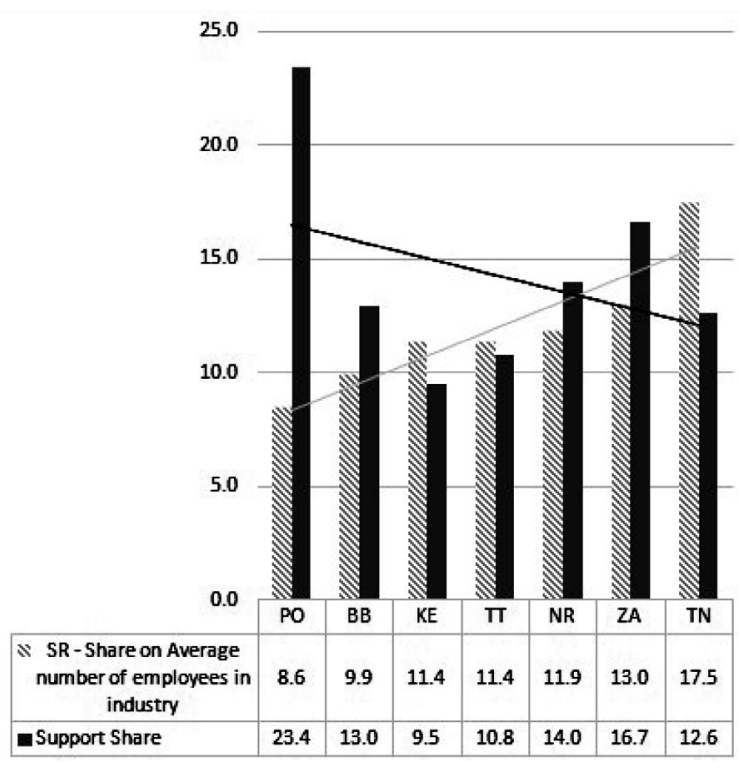


In the Czech Republic, the correlation between the share of employment in industry and shares gained in support of the region is 0.66 . The more employees in a given region, the more support the region received. In contrast, in Slovakia the trend was reversed. The correlation between the share of employment in industry and shares gained support in the region is -0.39 , so support was more directed to the regions that have a lower share of total employment in the industry.
When comparing the distribution of support with the unemployment rate in the regions, in the Czech Republic the correlation between these factors is -0.30 . So the larger share of support was distributed to the more developed regions. This corresponds more with the theoretical approach of spatially neutral policy. In the Slovak Republic, a correlation coefficient is 0.29 , more supporting the principle of concentration for the least developed regions. A more detailed data for the Czech Republic can be seen in the figure 4 .

\section{Fig. 4: Unemployment level vs. share of innovation support by regions in Czech Republic}

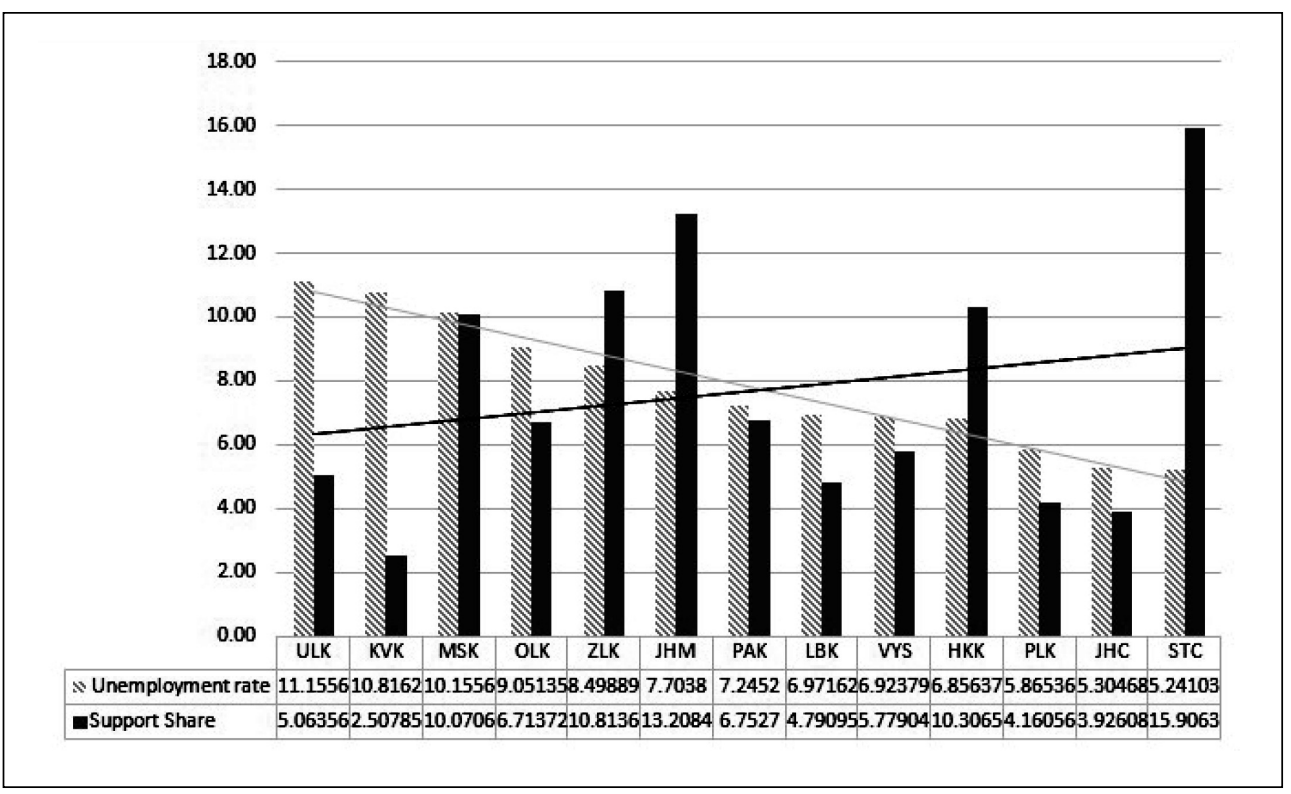

Source: own (dotted lines are simple trend regression lines, just to see trends more easily)

As we have seen from the above data, although support schemes in both countries are in terms of their objectives and evaluation criteria very similar, in fact, the final allocation is very different. While the Czech Republic is heading towards support of innovation in the more developed regions, the Slovak Republic support is concentrated in less developed regions. This confirms the fact that setting the types and forms of support are not sufficient factors for achieving the objectives and even with spatially blind policies, we could achieve very different regional distribution of support.

\section{High Tech Support Distribution}

One possible view at the regional distribution of support is also the analysis of the high-tech sector support. In terms of key indicators, both countries are similar. Both countries are relatively industrialized countries as the share of employment in industry in the Czech Republic is around 34\% and in Slovakia around 


\section{Ekonomie}

$31 \%$. Also the share of high and medium high manufacturing is comparable. In the Czech Republic the share is $41.92 \%(550,000$ out of $1,328,000$ employees in the industry) and in Slovakia $40.54 \%(223,000$ out of 550,000 employees in the industry) (Eurostat, 2015). Nevertheless, significant differences can be seen in the distribution of the support.

Generally, in the Czech Republic, a growing share of the industrial sector on total sales results in its growing share on the total amount of aid for innovation. In Slovakia, however, it is not typical that individual industrial sectors involved in the promotion have a similar share in total sales in the industry. Looking at the sectoral distribution of aid we found that more traditional sectors are supported more. The largest volume of support in the Czech Republic went into machinery, rubber and metals and in the Slovak Republic to rubber, food processing, wood processing and engineering industries. However, we mainly focused on the regional distribution of support for the high-tech sectors. We expected that the support for these sectors could generate the greatest added value and lead to more efficient use of support. Again, we wanted to find out whether the underdeveloped regions are able to develop appropriate projects in sectors with higher added value. The individual results are shown in figure 5 .

\section{Fig. 5: Share of high and medium high companies support as percentage of total support}

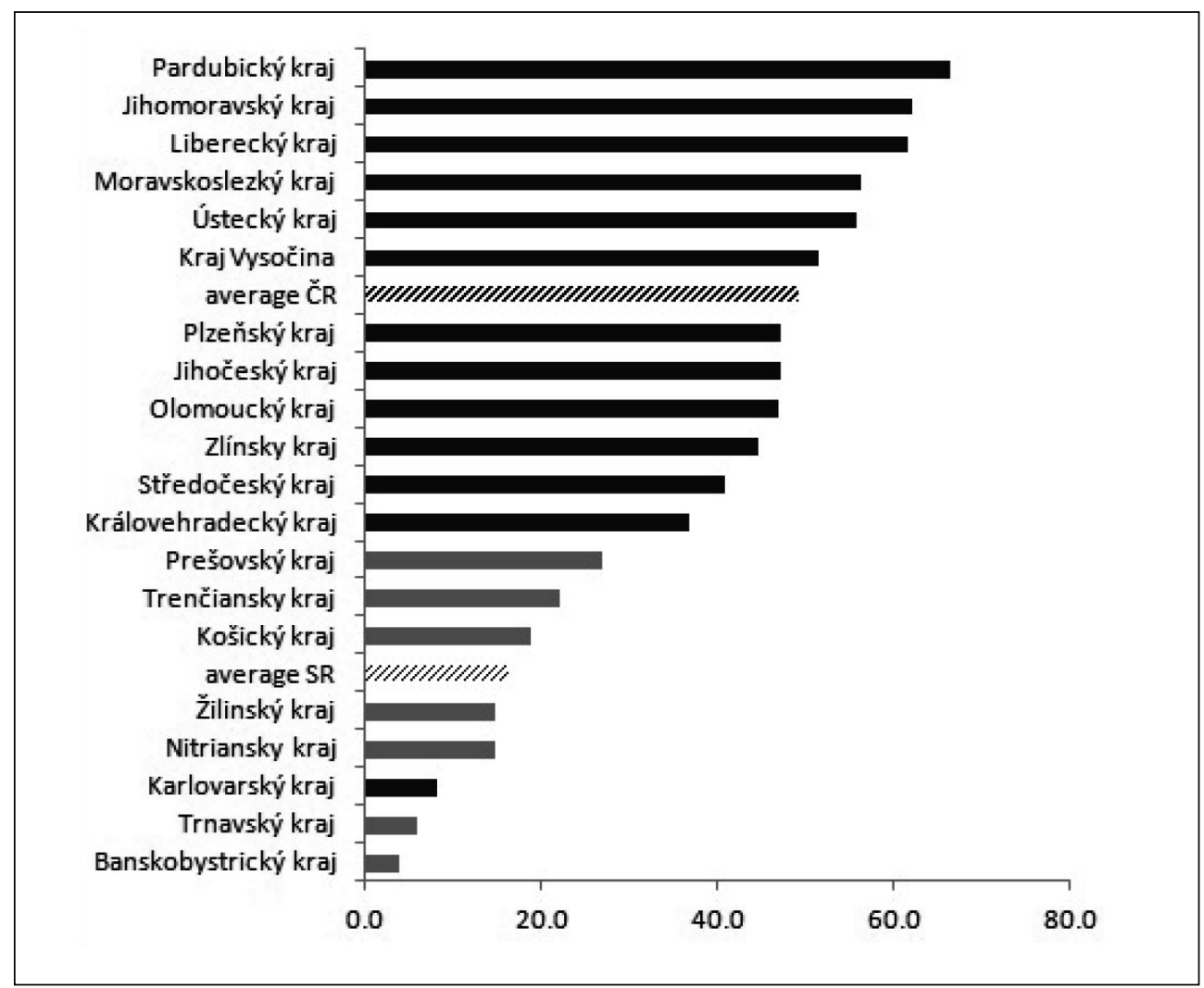


We see very different results between the Czech and Slovak republic (in figure 5 lighter grey are Slovak regions, darker grey are Czech regions). Although the proportion of the sectors in both countries is approximately the same, and the selection criteria were set in much the same way, the support is significantly different. While the Czech Republic indicates aboveaverage support for these sectors compared to their share of the total industry, in Slovakia, these sectors have been much less supported. With one exception, high tech and medium high tech sectors in all regions in the Czech Republic have been supported to a relatively greater extent than in Slovakia. Another interesting paradox is that in Slovakia, the sectors that have been the most supported are in the most backward region. Conversely, the proportion in the second most developed region in Slovakia was less than $10 \%$. Correlation between shares of high tech and GDP is 0.22 in the Czech Republic and -0.29 in Slovak Republic. The Czech Republic thus has a higher share of high tech industries being supported in more developed regions, contrary to the Slovak republic.

\section{Innovation Poles}

Support in the Slovak Republic had one more special feature. In developing national strategic reference frameworks, there has been established "innovation growth poles", with the focus on support of innovation. These poles were declared to be the most appropriate for achieving effective support to innovation in disadvantaged regions. The first major difference from the declared intention to allocate support to innovation growth poles can be seen in the fact that there were no additional points for projects from innovative growth poles. This confirms the important sectoral orientation support and then applying the spatially neutral policy. If we look at the real distribution of this support, we find that the innovation growth poles obtained $66 \%$ of the total support, which is more compared to the proportion of the population $(40 \%)$ in these cities, but again less than the proportional number of companies in these cities. So the real support was not concentrated in cities that have been declared as the most suitable for supporting innovation. This again shows difference between formal targets (concentrate support to innovation poles) and real distribution. This allocation follows the distribution of support on higher level (regions), where there was also support oriented towards the most lagging regions.

\section{Conclusions}

In the present article we examined the real distribution of European Union funds intended to promote innovation in two neighbouring member countries, namely the Czech Republic and Slovakia. Theoretical part was devoted to discussion between spatially blind and place based policy. We also looked at the role of innovation and the importance of the European Union cohesion policy evaluation. We dealt with important paradigms of development and its systems of support, the so-called place based policy vs. space neutral policy. We also discussed the issue of theory and practise of distribution of funds to the least developed regions.

The distribution of the support was very different among the regions. Regarding the average amount of aid for the project, Slovakia (approx. 915,000 EUR) is characterized by a higher amount than the Czech Republic (approx. 660,000 EUR). If we look at the amount of aid per capita, of all analysed NUTS 3 regions the first three places are the only regions of the Czech Republic with an amount of 153 to 110 EUR, while the Slovak NUTS 3 region Prešov takes the fourth place with 105 EUR per inhabitant. The least amount of this funding was earmarked also for Slovak Košice NUTS 3 region with a level of support of only 44 euros. We must also consider that the various regions are not internally homogenous, as there are large regional disparities, whether in the amount of aid but also in the level of development, which is examined more deeply in the next part of the research. We looked only at innovation poles at the city level and it confirmed that objectives of innovation support differ from real funds distribution.

Regional distribution of aid was examined in the context of level of development of individual regions and their share in the total amount of aid in both countries. Here, it needs to be emphasized that two very similar instruments of innovation support were analysed. In the Czech Republic, the more developed region is (measure by its share of GDP), the higher its share of the total amount of innovation support. Conversely, in Slovakia, the region that had the lowest share of GDP compare to other 
regions received most support from the EU. If we look at another indicator of development, the unemployment rate, the Czech Republic received the most support for regions with the lowest unemployment rate; while in Slovakia, we observe again an opposite trend - the region with the second highest unemployment rate had the largest share on total support.

In regards to sectoral distribution of support in both analysed countries, the largest share in overall support is given to industry; therefore we examined this sector in more detail than in other parts of the analysis. Generally, in the Czech Republic, as an industry increases its share on total sales, it also increases its share in the total amount of aid for innovation. In Slovakia, however, it is not typical that individual industrial sectors involved in funding will have a similar share of total sales in the industry. Most support went to subsectors of metal production and food. We also analysed the high tech sector separately and we again found very different results. While in the Czech Republic indicates above-average support for these sectors compared to their share of the total industry, in Slovakia these sectors have been much less supported.

Based on our evaluation of aid distribution, it should be noted that in spite of the same settings of support in each country, there is not the same real sectoral and regional distribution of support. To know which form of aid distribution is more effective, it is necessary to confront the results of the analysis with the impact of support measures, namely the extent of meeting the stated objectives of the instruments, such as how many patents were created with the help of the various regional and sector support. However, we confirm that even with spatially blind policy, the results could differ substantially in absolute placement of support distribution. This is again a field for further research. Cohesion policy should not only discuss the goals and forms of policies, but pay much more attention to hidden implementation factors, for example corruption or abilities of evaluators. It looks as if the evaluation process had influence on the distribution of support much more significant than the formal criteria or objectives set in the strategies. Another question that needs to be answered is the real impact of both systems.
This work was supported by the Scientific Grant Agency of the Ministry of Education, science, research and sport of the Slovak Republic, Grant No. VEGA-1/0098/15 and by the Slovak Research and Development Agency under the contract No. APVV-14-0512.

\section{References}

Asheim, B. R. T. (1996). Industrial districts as 'learning regions": a condition for prosperity. European planning studies, 4(4), 379-400. doi:10.1080/09654319608720354.

Acs, Z. J., \& Varga, A. (2002). Introduction to the special issue on regional innovation systems. International Regional Science Review, 25(1), 3-7. doi:10.1177/016001702762039358.

Barca, F. (2009). An Agenda for a Reformed Cohesion Policy: The Barca Report, Brussels. European Commission, DG Regio.

Barca, F., McCann, P., \& Rodriguez-Pose, A. (2012). The case for regional development intervention: placebased versus place-neutral approaches. Journal of Regional Science, 52(1), 134-152.

Bruno, R. L., Douarin, E., Korosteleva, J., \& Radosevic, S. (2015). Technology Choices and Growth: Testing New Structural Economics in Transition Economies. Journal of Economic Policy Reform, 18(2), 131-152. doi:10.1080/17 487870.2015.1013541.

Brusis, M. (2005). The instrumental use of European Union conditionality: regionalization in the Czech Republic and Slovakia. East European Politics \& Societies, 19(2), 291-316. doi:10.1177/0888325404272063.

Capello, R., \& Lenzi, C. (2013). Territorial patterns of innovation and economic growth in European regions. Growth and change, 44(2), 195-227. doi:10.1111/grow.12009.

Crescenzi, R. (2009). Undermining the Principle of Concentration? European Union Regional Policy and the Socioeconomic Disadvantage of European Regions. Regional Studies, 43(1), 111-133. doi:10.1080/00343400801932276.

Cooke, P., Uranga, M. G., \& Etxebarria, G. (1997). Regional innovation systems: Institutional and organisational dimensions. Research Policy, 26(4), 475-491. doi:10.1016/ S0048-7333(97)00025-5.

Dall'erba, S., \& Le Gallo, J. (2008). Regional convergence and the impact of European structural funds over 1989-1999: A spatial econometric analysis. Regional 
Science, 87(2), 219-244. doi:10.1111/j.14355957.2008.00184.x.

Eurostat. (2015). Appsso. Eurostat. Retrieved from http://appsso.eurostat. ec.europa.eu/.

Felixova, K. (2012). Evaluation of the absorption intensity of the entrepreneurial support in the regions funded intensely by the government. E\&M Ekonomie a Management, 15(5), 17-28.

Foray, D. (2014). Smart Specialisation: Opportunities and Challenges for Regional Innovation Policy (Region and Cities). Routledge.

MVaRR SR. (2007). Národný strategický referenčný rámec. Retrieved from http://nsrr.sk.

OECD. (2009a). How Regions Grow. Paris: Organisation for Economic Cooperation and Development. Retrieved from: http://www.oecd. org/regional/searf2009/42576934.pdf.

OECD. (2009b). Regions Matter: Economic Recovery, Innovation and Sustainable Growth. Paris: Organisation for Economic Cooperation and Development. Retrieved from: http://www.utas.edu.au/ data/assets/ pdf_file/0008/61937/REGIONS-MATTERECONOMIC-RECOVERY,-INNOVATION-ANDSUSTAINABLE-GROWTH-OECD-2009.PDF.

Ortega-Argilés, R. (2012). Economic Transformation Strategies: Smart Specialisation. Case Studies. S3 Smart Specialisation Platform. Retrieved from http:// freshproject.eu/data/user/01_public-area/ PP3_Policy_impact/Economic_transformation_ strategies.pdf.

Markusen, A. (1996). Sticky places in slippery space: a typology of industrial districts. Economic Geography, 72(3), 293-313. doi:10.2307/144402

Michálek, A. (2014). Disparity v alokácii a čerpaní zdrojov s dôrazom na marginálne regióny Slovenska. Geografický časopis, 66(3), 269-286.

Spišáková, E. (2011). Financovanie inovačných aktivít $v$ krajinách V4 prostredníctvom štrukturálnych fondov Európskej únie. Acta Oeconomica Pragensia, 19(3), 3-28.
Suurna, M., \& Kattel, R. (2010). Europeanization of innovation policy in Central and Eastern Europe. Science and Public Policy, 37(9), 646-664. doi:10.3152/03023421 0X12778118264459.

Šipikal, M., Pisár, P., \& Uramová, M. (2010). Support of innovation at regional level. E\&M Ekonomie a Management, 13(4), 74-85

Šipikal, M. (2013). Tailoring Innovation Policies to Sectors and Regions - The Case of Slovakia. Danube, 4(4), 277-291. doi:10.2478/ danb-2013-0015.

Tödtling, F., \& Trippl, M. (2005). One size fits all?: Towards a differentiated regional innovation policy approach. Research Policy, 34(8), 12031219. doi:10.1016/j.respol.2005.01.018.

World Bank. (2009). World Development Report 2009: Reshaping Economic Geography. Washington DC: World Bank. Retrieved from https://openknowledge.worldbank.org/ handle/10986/5991.

doc. Mgr. Miroslav Šipikal, PhD. University of Economics in Bratislava Faculty of National Economy Department of Public Administration and Regional Development miroslav.sipikal@euba.sk

Ing. Valéria Szitásiová, PhD. University of Economics in Bratislava Faculty of National Economy Department of Public Administration and Regional Development valeria.szitasiova@euba.sk

doc. Ing. Peter Pisár, PhD. Matej Bel University in Banská Bystrica Faculty of Economics

Department of Finance and Accounting peter.pisar@umb.sk

prof. Ing. Mária Uramová, PhD. Matej Bel University in Banská Bystrica Faculty of Economics Department of Economics maria.uramova@umb.sk 


\title{
Abstract
}

\section{SPATIALLY BLIND OR PLACE BASED POLICY? A COMPARISON OF INNOVATION SUPPORT IN THE CZECH AND SLOVAK REPUBLIC}

\author{
Miroslav Šipikal, Valéria Szitásiová, Peter Pisár, Mária Uramová
}

With the ongoing changes in development of the European Union, also conditions for financial support are changing. For Central Europe, most financial aid comes from Cohesion policies. The same applies for the support of innovations, which are considered to be a driving force of development. One of the main debates concerning cohesion policy is the issue of "placed based" versus "spatially blind" policies. Their role mainly differs within the area of economic growth. This paper deals with the evaluation of innovation support as a driving force for economic growth from structural funds in two neighbouring EU member states - in Slovakia and the Czech Republic. This article provides a picture of what kinds of policies are implemented and how consequently the resources of the European Union are territorially distributed to support innovation. We especially dealt with the question of the support criteria for projects and their role in the implementation of support. Based on this, the paper tries to identify where assistance is concentrated and how the criteria influence the geographical distribution of this support.

As a result, we found that, despite very similar spatially blind policies in both countries and very similar systems of providing support, they still have very different regional effects. In the Czech Republic, support was allocated to developed regions and high tech sectors to a greater extent. In the Slovak Republic, support was concentrated more on disadvantaged regions and in traditional sectors with lower added value. It shows the need to pay much more attention not only to policy set up, but also to policy implementation.

Key Words: Spatially blind policy, structural funds, cohesion policy, innovation support, place based policy.

JEL Classification: R58.

DOI: 10.15240/tul/001/2017-1-002 